\title{
Students' engagement with Facebook in a university undergraduate policing unit
}

\author{
Zoe Staines and Mark Lauchs \\ Queensland University of Technology, Australia
}

\begin{abstract}
Web 2.0 technologies are increasingly being used to support teaching in higher education courses. However, preliminary research has shown that students are using such technologies primarily for social purposes, rather than as a means of further engaging with academic content. This study examines a cohort of tertiary students' use of a Facebook page, which was created for a second year university policing unit at the Queensland University of Technology in Brisbane, Australia. Results from content analysis of the Facebook "wall" and a survey of student users and non-users showed that although students only demonstrated very little active engagement with academic content posted on the site (that is, they were reluctant to interact with unit materials in a way that would leave a digital trace), they reported that Facebook had increased their ability to engage with and critically analyse the unit content. In alignment with other research in this area, students also reported the usefulness of the Facebook page for increasing communication with their peers and with the teaching staff. This paper concludes by offering a number of best practice guidelines for the use of Facebook in tertiary education.
\end{abstract}

\section{Introduction}

Universities are not taking full advantage of web 2.0 to communicate with students, despite the benefits these technologies can offer in the teaching context (Smith \& Caruso, 2010). Web 2.0 technologies collapse social divisions created by time, space and culture, thereby creating new opportunities for networking and collaboration. Various technologies now allow individuals to share photos, updates, comments, news feeds, links to online media and details of their lives that could not previously be distributed with such ease. Facebook, one example of a web 2.0 technology, cites that its mission statement is to "...make the world more open and connected" (Facebook, n.d.). While the primary purpose of web 2.0 technologies has been to create networking opportunities, a variety of secondary benefits have also arisen. Social media platforms have been embraced by business, the creative arts and other fields. Conversely, the social media uptake into formal education, particularly at the secondary and tertiary levels, has been relatively cautious.

Students are already frequent users of web 2.0 technologies (Bicen \& Cavus, 2011; Madge, Meek, Wellens, \& Hooley, 2009). Prensky (2001) labelled all Generation-Y students "digital natives" whilst originally referring to teachers in higher education as "digital immigrants"; new technology users stumbling on to the virtual terrain of a younger generation. White, Sillipigni, Lanclos, Cornu, and Hood (2012) also made a similar distinction between digital residents (individuals with an ongoing online presence) and digital visitors (individuals who log on to the Internet with a specific purpose in mind and then $\log$ off once that purpose is achieved), though age is not a distinguishing factor here. In a later revision of his theory, Prensky (2009) claimed that his original distinction had become less relevant and instead suggested that the concept of "digital wisdom" may be more appropriate. Digital wisdom is that wisdom that arises from the use of digital technologies and the wisdom in the use of technologies to enhance individual capabilities (Prensky, 2009). Prensky $(2009$, p.1) stated: "...the digitally unenhanced person, however wise, will not be able to access the tools of wisdom that will be available to even the least wise digitally enhanced human." Thus, the key is not so much the presumption that all students will embrace digital technologies but the necessity that they should embrace them.

This paper presents an evaluation of a cohort of tertiary students' perceptions of the value of a Facebook page, which was established for a second year university policing unit at the Queensland University of Technology in Brisbane, Australia. The unit was taught during the first semester of 2012 and had an overall enrolment of 79 students. This study involved a content analysis of the unit's Facebook page, and a survey of student users and non-users of the page. This paper will commence with a review of the prevalence of web 2.0 usage by university students before exploring the literature on the use of this technology in the university setting. The paper will then present the data from this research project, 
discuss its relevance to the existing theory and conclude with recommendations for future practice and research.

\section{Students' use of web 2.0 technologies beyond the educational context}

Australian Communication and Media Authority figures show that 90\% of 18-24 year olds in Australia use $3 \mathrm{G}$ or smart phones (ACMA, 2011). In the same age bracket, 96\% use the Internet (Australian Bureau of Statistics [ABS], 2011). The use of social networking has also become more popular over time (Kennedy, Krause, Judd, Churchward, \& Gray, 2008; Smith \& Caruso, 2010). Smith and Caruso (2010) conducted a survey of college and university freshmen and seniors across 100 United States four-year institutions and general students at 27 United States and Canadian two-year institutions. Longitudinal data from 2007 - 2009 was also available for comparison (Smith \& Caruso, 2010). The authors found that respondents' use of social networking websites had increased slightly in the 18-24 years age group between 2007 and 2010, and had increased more dramatically in older age groups (i.e., 25 to 50 years and older) over the same period (Smith \& Caruso, 2010), which supports Prenksy's (2009) revision of the digital natives/digital immigrants divide. Smith and Caruso (2010) also found that social networking sites were used at some point by $94.1 \%$ of their sample of students between $18-24$ years, $85.7 \%$ of students between $25-29$ years, $81.5 \%$ of students between $30-39$ years, $69.2 \%$ of students between $40-49$ years and $58.1 \%$ of students aged 50 years or older. Facebook surpassed all other social networking sites as the "favourite", with $96 \%$ of respondents indicating that they used the site (Smith \& Caruso, 2010).

This preference for Facebook is also reflected in other studies. For instance, Selwyn (2009) found that $76 \%$ of his sample of 909 American undergraduate students maintained Facebook profiles. In a more recent study of 120 college students, Roblyer, McDaniel, Webb, Herman, and Witty (2010) found that 95\% had a Facebook account of which most checked between one and five times per day. Other studies have also found that students are heavy users of Facebook (Bicen \& Cavus, 2011; Yu, Tian, Vogel, \& Kwok, 2010;). Because of its widespread use, Facebook has been the focus of most research into the use of web 2.0 technologies in higher education.

\section{Take up and use of Facebook in educational settings}

Given the level of immersion students already have with Facebook and other social media, many researchers have suggested that these technologies should be integrated into educational settings (Bicen \& Cavus, 2011; Hung \& Yuen, 2010; McCarthy, 2010). It is assumed that the use of Facebook in educational settings is a natural extension of students' already heavy use of social media platforms in their private lives. However, the results of early empirical studies on the integration of Facebook into secondary and tertiary education have been mixed.

Merchant (2012) highlighted some perceived difficulties with the introduction of social networking sites into the education sector. These included: the perceived "danger" of open and unfiltered access to online interaction; suspicion of popular culture; a lack of familiarity with online social networking sites, which are still perceived to be the "province of the young"; and the absence of models of best practice to guide educators (Merchant, 2012, pp. 14-15). Merchant (2012) also noted the role of larger institutions in shaping and/or constraining the potential for the use of social networking sites in educational contexts as one area of difficulty. Institutions may be unwilling to embrace social networking sites, and instead may perceive them as a distraction to education rather than a tool to enhance it. This may be particularly apparent where institutions have invested in other internally run applications (for example, learning management system software) (Armstrong \& Franklin, 2008). Despite these barriers, teachers are increasingly experimenting with the use of such technologies. Where social media has been used to support education, its take-up by students varies.

Forty-nine percent of Smith and Caruso's (2010) sample indicated that they were using social networking technologies (including Facebook, MySpace, Bebo, LinkedIn and others) to collaborate in education courses. Forty-six percent of Madge et al.'s (2009) sample reported using Facebook for "academic purposes"; primarily to discuss academic work with other students and organise group meetings for project work. This distinction is also identified by Selwyn (2009), who found two key themes in students' educational uses of Facebook; to critically reflect on teaching experiences and to exchange practical "administrative-type" information. However, not all results have been so positive. Of Roblyer et al.'s 
(2010) sample of 120 college students, 92.5\% used Facebook for socialising with friends, while only $4.2 \%$ used it to communicate on class projects. In a study conducted by Selwyn (2009) into the use of Facebook by a sample of 612 undergraduate American students, only four percent of wall posts were related to study or the academic aspects of the university experience. This may be because of the existence of alternative, official systems such as Blackboard. It is also unclear how this relates to the actual amount of time students spend studying as opposed to socialising in their normal daily activities.

Cheung, Chiu, and Lee (2011) highlighted the importance of Facebook being used to facilitate collaborative learning. However, it is questionable whether or not students perceive this collaborative learning as helpful. In another study, secondary education students felt that they learned technology skills, creativity and communication skills by using MySpace (which has a similar wall space to Facebook) to facilitate their learning, but failed to see a connection between the use of this software and the skills and knowledge valued by their teachers (Greenhow \& Robelia, 2009). This may be because of the ways in which students use social media. For instance, Baran (2010) found that students tend to use Facebook in an informal manner and thus, will overlook some if not all messages, videos, pictures and links posted either by other students or the Lecturer. It may also be that students simply perceive such technologies primarily as a social tool and thus, cannot relate to them as support mechanisms for academic study. However, this may not necessarily represent the failure of such technologies in academia; benefits may also result from a primarily social use of Facebook in the educational context.

\section{Advantages of Facebook in educational settings}

Madge et al.'s (2009) study showed that a sample of undergraduate students from the United Kingdom used Facebook to establish social relationships at University, which reportedly aided their transition into the University setting. One respondent said Facebook made it easier to have group conversations, stating that "...all the emails get saved so organising things with friends is easier" (Madge et al., 2009, p. 146). Similarly, Hung and Yuen (2010) found that social networking sites had a positive effect on student interaction, which translated into additional learning opportunities and enhanced participation in the faceto-face classroom. The usefulness of Facebook in facilitating social connections may also be significantly more important for those students who would otherwise have difficulty with real world social interaction. For instance, Moore and McElroy (2012) found that extraverted individuals report significantly less frequent use of Facebook than introverted individuals. This also makes it attractive as an educational tool, as it may provide a means for less active class members to participate.

In addition to providing opportunities for collaboration, Baran (2010) found that Facebook was also useful in emphasising the teacher's availability to students. Similarly, Mazer, Murphy, and Simonds $(2009$, p. 179) found that "immediate" teachers - that is, teachers who demonstrate emotion, humour and a caring attitude towards their students via their online Facebook pages - were considered more trustworthy and caring by a sample of 129 American undergraduate students. Teachers should, however, be cautious to maintain consistency of self-disclosure in both the virtual and real teaching environments and be cognisant of the potential for unacceptable uses of Facebook pages, which may serve to damage teacher credibility (Mazer et al., 2009). While there is still very little literature on the most appropriate methods for using Facebook and other social media to encourage student participation, studies on the use of discussion forums in tertiary education provide some guidance in this regard.

\section{Approaches to using alternative online media in tertiary education}

Research into the use of discussion forums indicates that lecturers should be wary that when they make frequent posts, students are not necessarily encouraged to post more frequently and that this may actually reduce the length of discussion threads (Mazzolini \& Maddison, 2003; Mazzolini \& Maddison, 2007). Posts by lecturers may actually be perceived as an assessment tool, as opposed to posts made by students (Mazzolini \& Maddison, 2003). Thus, when using Facebook in tertiary studies it may be useful to give students clear instructions that the forum is only intended as an informal discussion area (Hew \& Cheung, 2007). However, it may also be the case that when Facebook discussions are not used as a tool for assessment students have little incentive to post (Dennen, 2008). Others have found that students also play a key role in facilitating online discussions and that instances where students provide personal opinions and question the opinions of others generally result in lengthier discussions (Hew \& Cheung, 
2007). Therefore, it may also be worthwhile for teachers to encourage students to share these types of information.

While Facebook may produce a range of advantages for tertiary education, there is still a paucity of empirical evidence of the use of Facebook in actual tertiary units and also very little guidance about how Facebook should be used to achieve best practice. At a specific level, the authors of this paper could not source any studies that focus primarily upon students' use of Facebook in the educational context of justice and policing (though Madge et al.'s, 2009 and Selwyn's, 2009 studies did include criminology and law students in a broader sample of university undergraduates).

\section{Research problem}

This study seeks to contribute to the existing literature by further examining students' use of a unit-related Facebook page in an undergraduate university class. Based on past studies, this research proposes the following hypotheses:

1. The rate of Facebook usage in the unit will be high, matching the figures for Facebook usage in other studies;

2. Students will primarily use the unit Facebook site for communicating and connecting with the Lecturer and their peers, as opposed to further engaging with academic materials;

3. Since students are already heavy users of Facebook, they will use the unit Facebook site to ease the completion of the unit's group work assessment item.

Additionally, this paper also poses some preliminary best practice guidelines on the use of Facebook in tertiary education, which have so far been absent from the literature (Merchant, 2012). These recommendations are based on the authors' experiences during this study and appear in the final Lessons learnt section of the paper.

\section{Method}

In the tertiary policing unit that is the focus of this paper, Facebook was integrated as a means for increasing students' engagement with one another, the Lecturer and unit-related information. The unit contained a group work element for one of its assessment items and thus, the Facebook site (alongside other technologies such as Google Docs) was promoted as one way to make group work easier. The Lecturer used the page to relay administrative messages and updates about the unit content, assessment items and teaching timetable. The Lecturer also posted extra-curricular materials (for example, news articles) that related to the unit content. The intention of this exercise was to encourage further engagement with the topics covered in the unit and to therefore enhance student learning. It was also intended that the ongoing contact between students and their peers, and between students and the Lecturer, would help to create a more supportive learning environment and an improved community of practice (Hung \& Yuen, 2010). Although the unit was also supported by a central university learning management website (Blackboard), Facebook has much better discussion capabilities.

Students were alerted to the existence of the Facebook page during the first lecture of the semester, as well as via an announcement (also sent via email) made through the Blackboard page. Due to potential inequity issues (Armstrong \& Franklin, 2008), the Lecturer also duplicated all notifications that were made on Facebook through the Blackboard site; a point that was relayed to students early on. Students were advised at the outset that it was up to them whether or not they wished to access the Facebook site and that they would not be disadvantaged if they did not.

This paper takes a triangulated approach to understanding students' use of the unit's Facebook page. First, a content analysis of all posts on the Facebook wall during the semester enabled the authors to understand the different uses of the Facebook page by the Lecturer (that is, the first author of this paper) and students. Where the Lecturer or students posted directly to the Facebook wall, these are referred to as primary posts. Where the Lecturer or students posted responses to primary posts, these are referred to as secondary posts. The posts were initially divided into primary and secondary categories. A thematic coding approach was then used, whereby emerging themes were coded and content analysed. For example, the intentions of the post (that is, to seek social interaction, elicit administrative information about the subject or provide/seek extra-curricular materials etc.) as well as the responses to the post (that 
is, whether responses demonstrated insight into the subject matter of the unit or were simply administrative in nature) were considered.

Secondly, an online questionnaire was distributed to all students enrolled in the unit (that is, those who used the unit's Facebook page and those who did not) to determine why they did or did not engage with the Facebook site and if they did, whether it aided their studies and/or helped to foster contacts with their peers. Students who did engage with the Facebook page were also asked whether the page was used to facilitate a group work component of the unit's assessment. The survey was hosted via the online service provider SurveyMonkey, which allowed the survey uniform resource locator (URL) to be distributed to all students via their university email addresses. Students could click on the URL and be taken directly to the survey page. They could choose to opt out of the survey at any time by closing their browser window. Respondents were offered the chance to win one of two $\$ 30$ gift vouchers for an online bookstore as an incentive to complete the survey. Students could decide whether to complete the survey anonymously (and not enter the competition) or enter their name at the end of the survey (and enter the competition). The vouchers were merely offered as an incentive to complete the survey, and not as an incentive for students to identify themselves. Students were, at all times, assured that their responses were entirely anonymous and would not impact upon their grades in any way.

\section{Results and discussion}

The questionnaire was distributed to all 79 students enrolled in the unit. A total of 38 questionnaires were completed; a response rate of $48 \%$. The available demographics of the unit population, Facebook users and survey sample are outlined in Table 1.

Table 1

Demographics of unit population, survey sample and unit Facebook users

\begin{tabular}{llccc}
\hline \multicolumn{2}{c}{ Demographic } & $\begin{array}{c}\text { Unit population } \\
(n=79)\end{array}$ & $\begin{array}{c}\text { Unit Facebook users } \\
(n=49)\end{array}$ & $\begin{array}{c}\text { Survey sample } \\
(n=38)^{*}\end{array}$ \\
\hline Gender & Male & $21(27 \%)$ & $8(16 \%)$ & $3(8 \%)$ \\
& Female & $58(73 \%)$ & $41(84 \%)$ & $34(91 \%)$ \\
\hline Age & Under 18 & Data not available & Comparative data not \\
& $18-21$ & & & - \\
& $22-25$ & & & $29(78 \%)$ \\
& $26-29$ & & & $5(14 \%)$ \\
& $30-33$ & & & $1(3 \%)$ \\
& $34-37$ & & & - \\
& $38-41$ & & & - \\
& $42-45$ & & & $1(3 \%)$ \\
type & $46-49$ & & & - \\
\hline
\end{tabular}

Note. All percentages are rounded upwards to the nearest whole number *One value missing as one respondent chose not to answer these demographic questions.

Most students $(86.5 \%)$ identified on their respective Facebook pages as being aged between $18-24$ years, while $9.6 \%$ of students were aged between $25-34$ years, $1.9 \%$ were aged between $35-44$ years and $1.9 \%$ were aged 55 years or over. While it is assumed most people enter correct information, the personal information (including age) entered into Facebook is not externally verified.

The following results are presented in response to the three research hypotheses proposed in this study. The actual take-up of the unit Facebook site is initially described before the nature of students' usage is discussed. Finally, the study outlines the students' use of the unit Facebook page to collaborate on a group work assignment 


\section{Take-up and usage of unit Facebook page}

Initially, take-up of the unit Facebook page was quite fast, though it quickly tapered off. Overall, 52 students ( $66 \%$ of the total enrolment of 79 students) had "liked" the page by the end of the teaching semester, which meant that they agreed to receive updates and news feeds on their Facebook home page. Three of those students became inactive during the semester (that is, they became absent without leave) and were therefore removed from the sample, leaving 49 students in total. Forty students "liked" the page within the first week of the semester.

Of the 38 students who responded to the questionnaire, $35(92 \%)$ indicated that they had accessed the unit Facebook site during the semester, while three (eight percent) indicated that they had not. The three students who indicated that they did not access the unit Facebook page gave the following reasons:

- I do not see the purpose of using Facebook for university $(n=2)$;

- I would prefer to use Blackboard for my studies $(n=3)$;

- I would prefer to use email for my studies $(n=3)$.

No students indicated that they did not have a Facebook account, or that they only perceived Facebook as a tool for socialising with family and friends. Of those three students who chose not to access the unit Facebook page, two indicated that Facebook is not a useful addition to support university units while one student thought it was a useful support. The two students who thought it was not useful stated:

Though I do think that Facebook is a great tool for communication, I would assume that anything said on Facebook of any value to my studies would be mirrored on Blackboard or via email... If this is not the case and information is shared to Facebook participants that cannot be gained elsewhere, it disadvantages people who are unable to gain access to Facebook. (respondent 7)

I think Uni studies should be kept separate from social networking sites. You should be able to get everything you need from Blackboard (it has discussion boards) emails, lectures etc. It just adds another unnecessary thing. (respondent 33)

The one student who thought it was useful in supporting tertiary units of study stated that it was useful "...to hear comments from other students" (respondent 26). The key issue indicated by respondents seven and 33 was the perception that Facebook did not have any capabilities that the Blackboard site did not and, thus, could not add value. While Facebook cannot subsume all of the capabilities of the Blackboard site (for instance, it cannot be used to upload unit materials or non-public documents), its discussion capabilities are far greater. In this regard, the unit Facebook site was intended to complement rather than replace Blackboard, and this was relayed to students at the beginning of the semester.

Of the 35 survey respondents who had accessed the Facebook site, 31 (89\%) indicated that they had chosen to "like" it while four (11\%) students chose not to "like" the page, though three of the four accessed the page at least one more time during the semester. The student who chose not to "like" the Facebook page, or access it again during the semester indicated that they did so because they could not see the purpose of using Facebook for university. No further explanation was given. The frequency of access for those 34 students who did use the unit Facebook page during Semester one 2012 is displayed in Figure 1. 


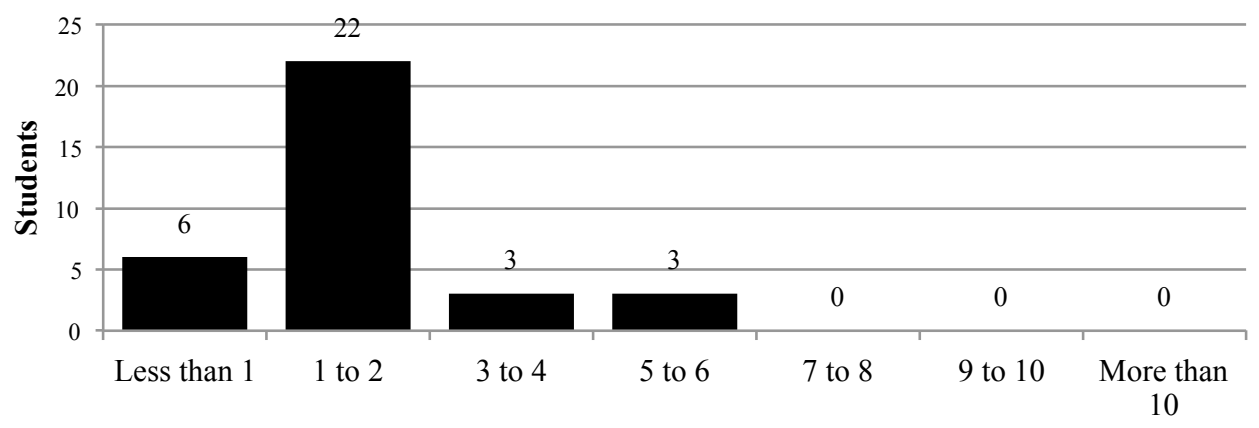

Times per week

Figure 1. Number of times per week students accessed unit Facebook page $(n=34)$.

Note. Some values are missing since not all respondents answered this question.

Overall, the above results indicated a considerable immersion with social networking tools such as Facebook. This is consistent with the findings of other studies that have also demonstrated students' heavy use of social media, including Facebook (Bicen \& Cavus, 2011; Madge et al., 2009; Roblyer et al., 2010; Selwyn, 2009; Smith \& Caruso, 2010; Yu et al., 2010). However, while take-up of the Facebook page was relatively high, student contributions to the page were reasonably low.

\section{Nature of Facebook use}

The content analysis of the wall of the unit's Facebook page indicated that the majority of primary posts were contributed by the Lecturer, rather than students. Of the 34 primary posts contributed to the wall (as opposed to secondary posts, which respond to primary posts) $29(85 \%)$ were made by the Lecturer. Nine (31\%) of the Lecturer's posts attempted to engage students in discussion about unit materials or external news articles that related to the unit content. The Lecturer's remaining $20(69 \%)$ posts were primarily administrative in nature. That is, they relayed information about tutorial and lecture times or locations, where to access unit materials and the processes and due dates for submitting assignments.

Overall, students made five (15\%) primary posts on the Facebook wall. Four of these directly addressed the Lecturer, while a fifth post aimed to solicit the student's peers to join a group for a university-run competition. Three of the student posts related to administrative matters (assessment items and the release of associated grades) while one post demonstrated reflection on extra-curricular materials related to the unit:

Hi [Lecturer's name], I hope I'm not over stepping my bounds but I think this is something of extreme interest to Justice students, especially those who may be studying Justice with the hopes of getting into the police force. I would like to know your thoughts and feelings on this...

The student posted a link to an online newspaper article about changes to recruitment measures for the Queensland Police Service. Firstly, it is interesting that the student appeared concerned that a primary post of this nature was "overstepping their bounds". At the beginning of the semester, students were advised that the Facebook page was there to allow them to communicate and discuss unit-related issues, as well as receive updates. This comment demonstrated, however, that more explicit instructions were required. Although the student requested feedback from the Lecturer and fellow students, only the Lecturer provided a response. The student who had originally posted then engaged with the Lecturer's initial response and sought further feedback:

...Many people commenting on the [online] article have articulated that our current commissioner was a product of the cadet style of recruiting, but I think it's illogical to hinge one man's achievements on the direction of a very important branch of the public service... 
These comments demonstrated good insight into the implications of the proposed changes discussed in the newspaper article. In addition to making primary posts, students also made secondary posts and "liked" some of the posts made by the Lecturer. There were 27 secondary posts in total, $14(52 \%)$ of which were made by students. There were also a total of 53 "likes" on the page, $43(81 \%)$ of which related to the Lecturer's administrative posts. Most of the secondary posts were also administrative in nature (for example, one student asked whether an online tutorial session was recorded and where they could find it), though one secondary post by a student did demonstrate further engagement with the unit materials. This post was made in response to the Lecturer's primary post, which included a link to an online news clip from the United Kingdom concerning the reduction of bureaucracy in policing. A student commented the following:

I hear often enough from the various police officers that I know that there is a HUGE amount of paperwork involved in policing. If there is a way to cut that back, but refrain from negatively impacting the quality and purpose of their duties as police, then I think it would be a great idea.

The Lecturer indicated support by "liking" this post. This comment displayed reasonable insight into and reflection upon the impact of bureaucracy in policing; a key topic of discussion during the week that this post was uploaded. However, only one student responded to the Lecturer's post and furthermore, no other secondary posts on the Facebook wall demonstrated insight into the unit materials. This was similar to English and Duncan-Howell's (2008, p. 598) finding that wall posts on a unit-specific Facebook page require a substantial amount of "seeding" by the Lecturer. Most discussion topics were established by the Lecturer, rather than by students (English \& Duncan-Howell, 2008). Furthermore, none of the primary or secondary posts could be considered predominantly "social" in nature, which was a departure from the findings of some previous studies (Robyler et al., 2010; Selwyn, 2009). Despite this, the ability for students to become more familiar with the Lecturer and with each other's names online did, in the opinion of the Lecturer, create a more supportive learning environment during classroom sessions.

Although the above results demonstrate very little evidence of student engagement, survey results allowed the researcher to delve deeper into the uses of Facebook that did not necessarily leave a digital trace. When asked how they used the unit Facebook site, students indicated a number of reasons that were both social and academic. These are illustrated in Figure 2.

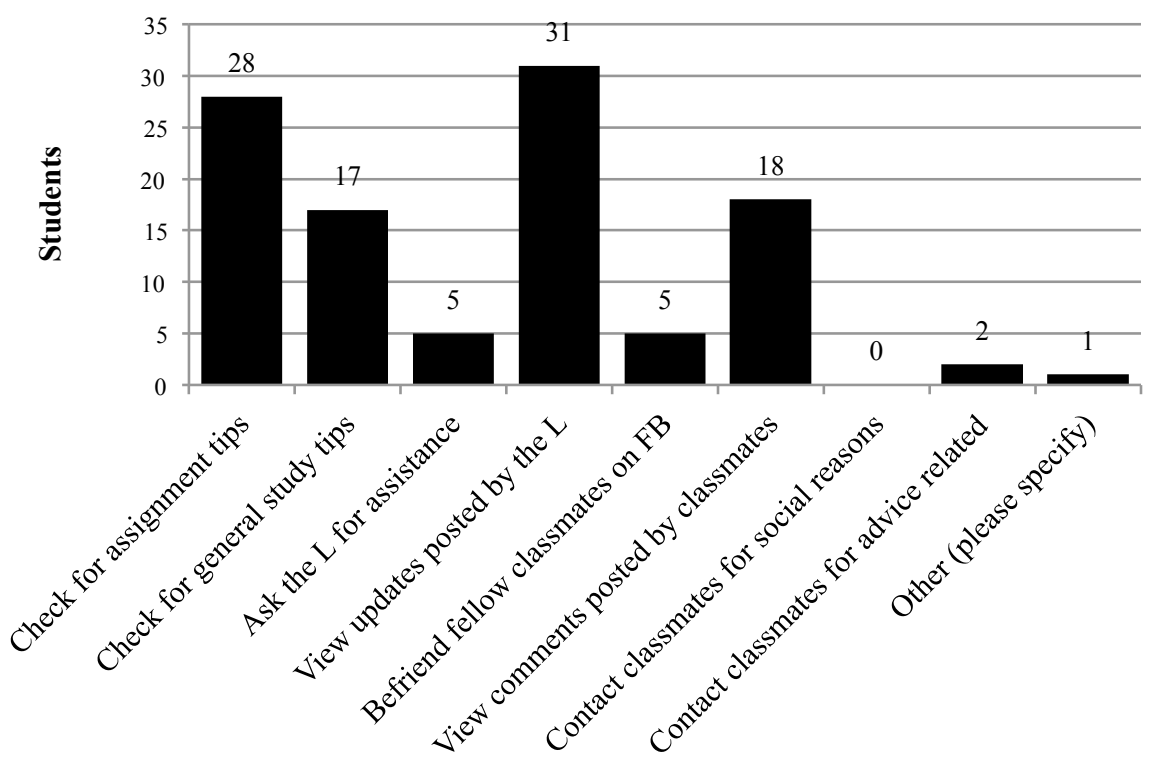

Figure 2. Uses of the unit Facebook site $(\mathrm{n}=34)$.

Note. $\mathrm{L}=$ Lecturer, $\mathrm{FB}=$ Facebook. Some values are missing since not all respondents answered this question. 
The student who answered other in Figure 2 stated:

...to reply to articles of interest posted by [the Lecturer] also to post articles I thought were interesting and wanted to know [the Lecturer's] opinion of. (respondent 28)

Students were also asked how useful the unit Facebook page was across a range of areas. The responses are illustrated in Figure 3. In order to gauge the usefulness of the unit Facebook page in comparison to the Blackboard site, students were then asked to indicate whether Facebook was worse or better than the central web site across a range of areas. The students' responses are outlined in Figure 4.

The results showed that, although students rarely posted on the Facebook wall, Facebook was very useful for easing communications between students and teachers, information sharing and, surprisingly, engagement with unit materials. As shown in Figure 2, most students accessed the site to view updates posted by the Lecturer, check for assignment tips, view comments posted by classmates and check for general study tips. Only very few indicated that they had used the site for predominantly social reasons. When asked about the usefulness of Facebook across a range of areas, most students indicated that it was useful across all areas. In particular, it was most useful for making contact with the Lecturer $(M=3.18$, where 1=not useful, 2=somewhat useful, 3=useful, $4=$ extremely useful $)$ and peers $(M=2.76)$ though it was also very useful for knowing and understanding unit content $(M=2.36$ and $M=2.39$ respectively), performing in assessment $(M=2.33)$ and critically analysing unit content $(M=2.12)$. Again, although it was primarily useful as a means for communication, unexpectedly high responses were received in relation to the usefulness of Facebook for academic purposes. The results in Figure 4 also support the findings of Figures 1 and 2; that Facebook is slightly more useful for easing communication than actually accessing information about topics covered in the unit and/or accessing information about assessment. Of course, Facebook is unable to host whole documents such as study guides, readings, assessment information and the like; the key purpose of the Blackboard site.

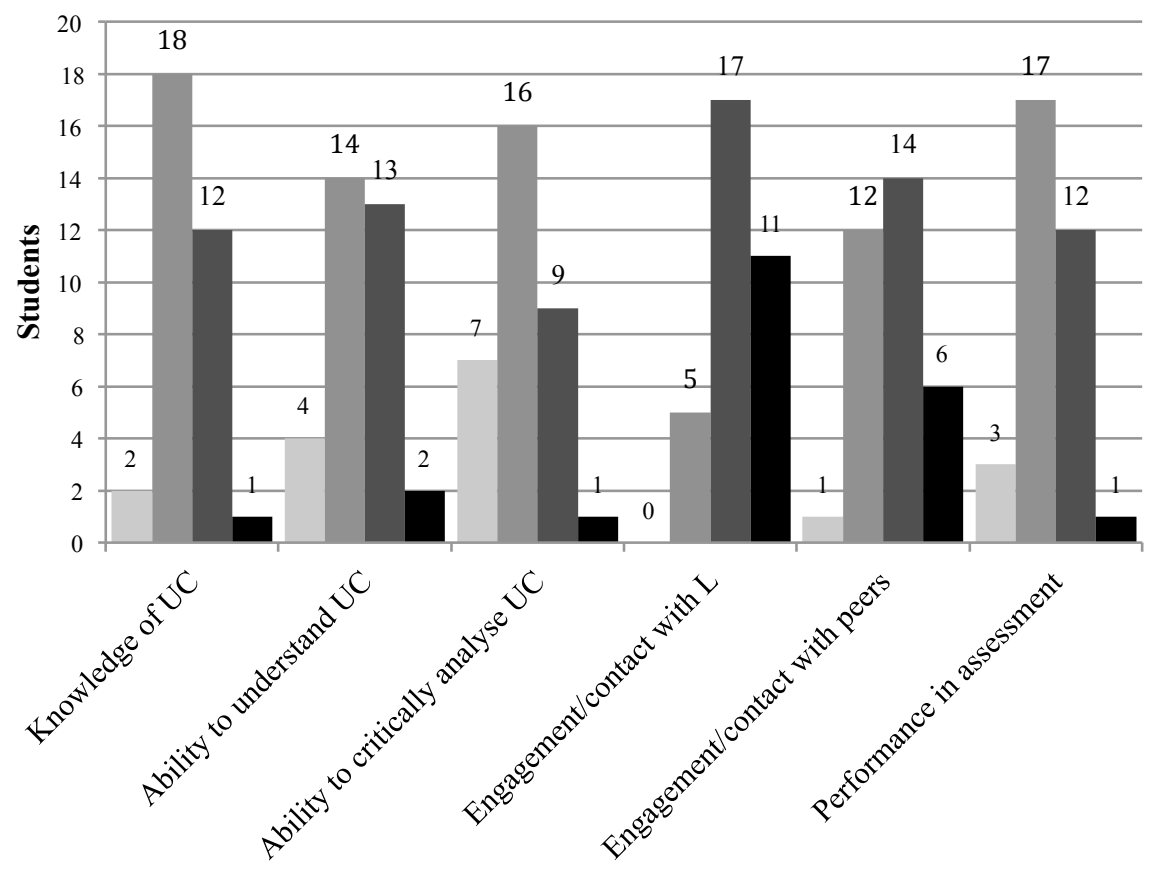

Not useful

- Somewhat useful

Useful

- Extremely useful

Figure 3. Usefulness of unit Facebook page across a range of areas $(n=33)$.

Note. $\mathrm{L}=$ Lecturer, $\mathrm{UC}=$ Unit Content. Some values are missing since not all respondents answered this question. 


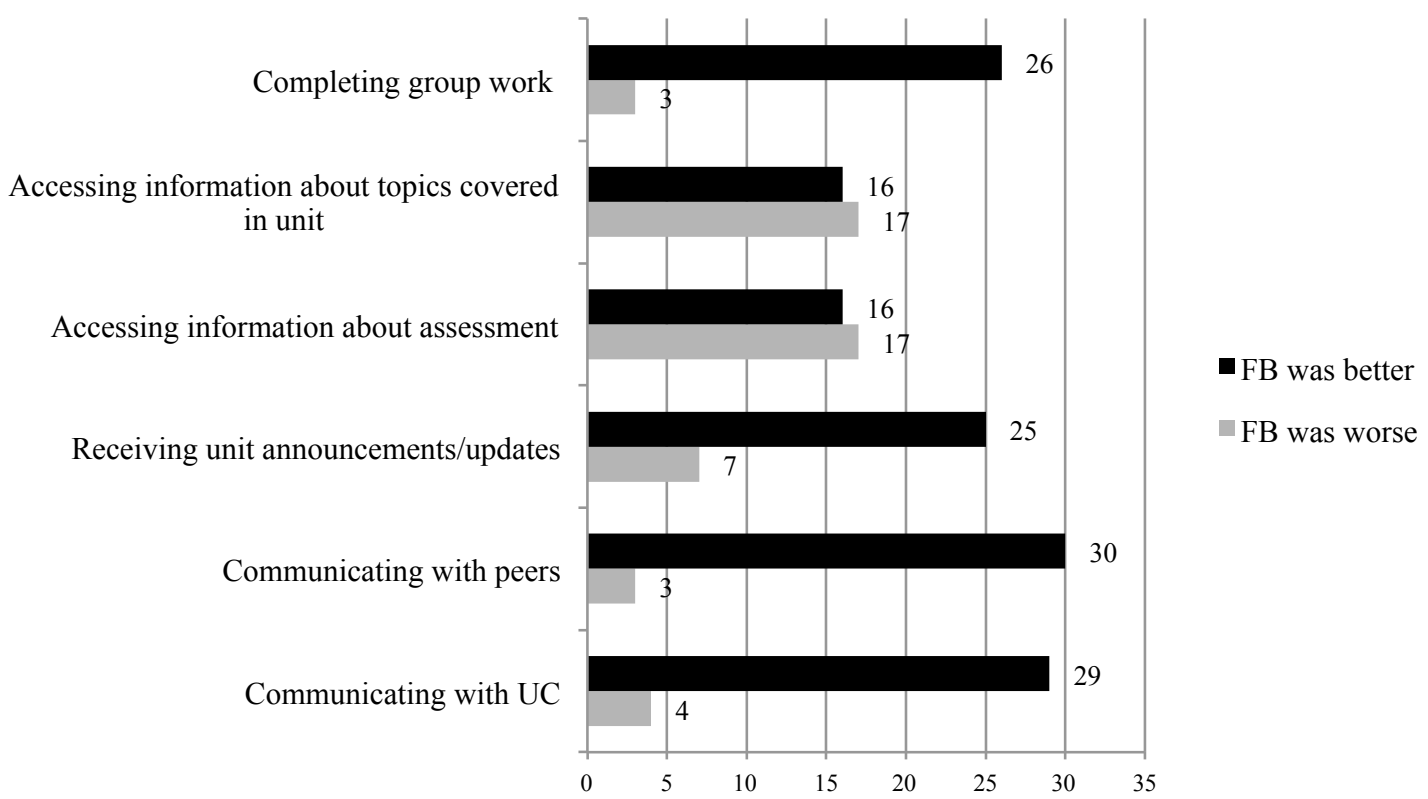

Figure 4. Usefulness of unit Facebook site compared with University's central web site $(\mathrm{n}=33)$.

Note. $\mathrm{UC}=$ Unit Coordinator. Some values are missing since not all respondents answered this question.

Based on previous studies, the researcher expected to find that students had used Facebook for predominantly social rather than academic purposes (Baran, 2010; Cheung et al., 2011; Madge et al., 2009; Selwyn, 2009). However, an unexpectedly high number of students reported using the site to further engage with the unit content. This finding was also supported by responses to a final survey question that asked respondents whether the Lecturer could have used Facebook differently. Many students indicated that they would have liked the Lecturer to post more frequent comments and updates regarding the unit materials (respondents 4, 9, 14, 20, 24, 36, 38). Specifically, respondent 38 stated that the Lecturer could "Have more constant updates and have some more useful media examples to engage with the unit content." This was surprising, given the lack of primary and secondary posts contributed by students to the Facebook wall. Although the content analysis indicated that students did not provide evidence (in the form of primary and secondary posts or "likes") of engagement with academic posts, it may be the case that this engagement was occurring in a more passive manner and thereby, leaving no digital trace (Beaudoin, 2002). The fact that students requested more information was encouraging and, in contrast to the findings of some studies (Mazzolini \& Maddison, 2003; Mazzolini \& Maddison, 2007), indicated that educators should be buoyed to use Facebook to convey unit-related information more frequently.

\section{Use of Facebook for group work assessment}

When asked whether they had used the unit Facebook page to help complete a group work assignment, nine (27\%) answered "Yes" and $15(44 \%)$ answered "No" (the remaining $10(29 \%)$ indicated that they were external students and thus, were not required to complete the group work assignment). Of those 15 students who did not use the unit Facebook page to complete group work, most $(n=12)$ stated that it was easier to contact their group via telephone and/or email (including via the Blackboard site's email capability) (respondent 13). Interestingly, one respondent indicated that their group had created their own Facebook page to work on their group assessment item (respondent 8), while another two respondents indicated that they used private messaging on Facebook or posts on their private Facebook pages to communicate with their group members (respondents 20 and 28).

Of those nine students who indicated that they did use the unit Facebook page to assist with group work assessment, eight indicated that it was helpful while one indicated that it was not. Most of the eight students who did find the page helpful indicated that it aided communication between group members. In particular, multiple group members could view discussion streams without the fuss of having to forward and copy emails (respondents 10,21,36) and group members could generally be found and contacted 
more easily (respondents $10,12,15,27,36,38$ ). One respondent indicated that the Facebook page was easier because it allowed them an alternative to speaking face-to-face:

...Furthermore, for me personally, I am not really good at talking face to face, and by discussing things via text I find it easier to express ideas. (respondent 10)

This supported Moore and McElroy's (2012) finding that introverted individuals are more likely to use Facebook. The ability to carefully consider comments or responses is a clear benefit of an online environment, as opposed to the immediate nature of classroom interaction (McCarthy, 2010). Other students indicated that the page helped them to check for updates regarding assessment (respondents 15, 38) and provided their group with links to relevant information (respondent 37). The student who answered that the unit Facebook page was not helpful for group work gave the following reason:

Because there was $[\mathrm{sic}]$ two of us in the group and once we had added each other on Facebook we then spent the rest of the time texting each other instead. (respondent 9)

The low take-up of the unit Facebook site for assisting with the group assignment reflected the previous findings of Robyler et al. (2010); that only a small fraction of students use Facebook to communicate on class projects. While it is evident that Facebook may not be useful in all cases (for instance, where groups only consist of two or so students, as indicated by respondent 9), the above comments indicate that there are some benefits to be gained. In this regard, it may be worthwhile to promote the use of Facebook to students as an easy method of communicating with one another for group work. This may extend beyond a unit's Facebook site; students may feel more comfortable using their own Facebook pages for communication (as indicated by respondents $8,20,28$ ).

\section{Lessons learnt}

The study results showed full support for the first research hypothesis: 1) that the rate of Facebook usage would be high, matching the figures for Facebook usage in other studies. Surprisingly, only partial support was found for the second and third hypotheses: 2) that students would primarily use the unit Facebook site for communicating and connecting with the Lecturer and their peers, as opposed to further engaging with academic materials; and 3) that students would use the unit Facebook site to ease the completion of a group work assessment item. It appeared that students engaged with the unit materials at a greater rate than has been shown in previous studies, though this engagement rarely left a digital trace. Furthermore, students did not use the unit Facebook site for group work as much as expected, despite their otherwise heavy use of social media.

Because there is still very little best practice guidance on how to use social media in higher education (Merchant, 2012), it seems appropriate to reflect on some lessons learnt from the use of Facebook described in this paper. First, it appears that overall, Facebook was perceived by students as a useful addition to traditional teaching approaches. This is reflected in their high take-up of the unit Facebook page. Additionally, 32 (97\%) students stated that Facebook was a useful support to tertiary units in response to one survey question. Students were given the option of further explaining their responses; 15 $(45 \%)$ chose to do so. They gave the following reasons:

- Unit information was easier to access when posted on Facebook as opposed to the central university website (respondents 2, 3, 8, 9, 10, 15, 17, 23, 24, 28, 31, 36).

- $\quad$ Students are more likely to check Facebook as opposed to the Blackboard site (respondents 9, 11, 15, $17,21,28)$.

- $\quad$ Facebook allows for more discussion and clarification of ideas (respondents 3, 11).

- Most students are on Facebook anyhow, so it may as well be used to support students' studies (respondents 5, 24, 28). 
Respondent 10 also cautioned that although Facebook is beneficial in some ways, it should not replace the central university website, as it is less secure and may disadvantage some students who do not have a Facebook account. This supports the usefulness of Facebook as a complementary mechanism (rather than a replacement) for central university websites in tertiary education.

Respondent nine stated that Facebook is a "...very modern and accessible tool for uni students... probably the best way to communicate and interact with them." Two other respondents suggested that Facebook should be used again in the future (respondents 14, 17) while respondent 28 stated that the unit Facebook site was a good method of "embracing technology" and that the Lecturer had gone "...above and beyond the support most university staff provide". Based on the findings described in this paper, some suggestions for academics who intend to use Facebook in the future are presented below:

- Teachers should not be afraid to use Facebook to make non-administrative posts about unit content. Students in this research requested that the Lecturer post more unit-related materials, even though they did not leave digital traces of active engagement on the Facebook wall.

- Teachers should make a concerted effort to provide more explicit instructions regarding the use and purpose of the Facebook page so students feel comfortable with making primary posts and actively engaging with comments and posts made by others.

- One respondent in this research suggested that teachers should consider setting up their unit Facebook sites as "groups" rather than "pages" (respondent 8). That respondent indicated that this would provide for "...easier access [and] better discussion abilities" (respondent 8). This would have also overcome a problem mentioned by respondent 10 ; that the site should be restricted only to subscribed users, rather than being publicly available.

- Teachers should trust students to make acceptable use of unit Facebook sites. This study did not provide any support for Merchant's (2012) caution about the "danger" of open communication in an unregulated environment and furthermore, Facebook's administrative tools can be used to deal with cases of unsuitable use, should they arise (McCarthy, 2010).

- Teachers should encourage the use of Facebook to ease communications regarding group work assessment items, though students may choose to use their own private Facebook sites rather than unit-related sites to this end.

\section{Conclusion}

Because of the exponential growth of online social networking in the previous decade, there have been increased calls to incorporate web 2.0 technologies such as Facebook into teaching approaches. Empirical evidence of the uses of Facebook in higher education is slowly emerging, but there is still much to learn. This paper contributes to the growing pool of evidence, which shows that Facebook can be successfully used to support university learning. It can provide an excellent mode of communication between students and lecturers, but can also encourage further engagement with unit materials and topics. This paper concluded with some suggestions for future uses of Facebook at university. These suggestions are not intended to be all-encompassing; there is still much to learn about the best approaches in this area. Future research should endeavour to further test and consolidate the findings of this study with additional empirical evidence. Indeed, the ways in which students interact with such sites and their best practice use is still an emergent area of research and thus, a larger body of empirical evidence is required before a comprehensive best practice framework can be developed.

\section{References}

Armstrong, J., \& Franklin, T. (2008). A review of current and developing international practice in the use of social networking (Web 2.0) in higher education. Retrieved from http://www.franklinconsulting.co.uk/LinkedDocuments/the \%20use \%20of\%20social\%20networking\%20in\%20HE.pdf 
Australian Bureau of Statistics (ABS). (2011). 8146.0 - Household use of information technology, Australia, 2010-11. Retrieved from http://www.abs.gov.au/ausstats/abs@.nsf/Latestproducts/D11394A54F8B9ED1CA25796600152C62? opendocument

Australian Communications and Media Authority (ACMA). (2011). Communications report 2010-11 series: Report 3 - The emerging mobile telecommunications service market in Australia. Canberra: ACMA.

Baran, B. (2010). Facebook as a formal instructional environment. British Journal of Educational Technology, 41(6), 146-149.

Beaudoin, M. (2002). Learning or lurking? Tracking the 'invisible' online student. Internet and Higher Education, 5, 147-155.

Bicen, H., \& Cavus, N. (2011). Social network sites usage habits of undergraduate students: case study of Facebook. Procedia - Social and Behavioural Sciences, 28, 943-947.

Cheung, C., Chiu, P.Y., \& Lee, M. (2011). Online social networks: Why do students use Facebook? Computers in Human Behaviour, 27(4), 1337-1343.

*Dennen, V. (2008). Looking for evidence of learning: Assessment and analysis methods for online discourse. Computers in Human Behaviour, 24, 205-219.

English, R., \& Duncan-Howell, J. (2008). Facebook goes to college: Using social networking tools to support students undertaking teaching practicum. MERLOT Journal of Online Learning and Teaching, 4(4), 596-601. Retrieved from http://jolt.merlot.org/vol4no4/english_1208.pdf

Facebook. (n.d.). Newsroom. Retrieved November 15, 2013 from http://newsroom.fb.com/content/default.aspx?NewsAreaId=22

Greenhow, C., \& Robelia, B. (2009). Informal learning and identity formation in online social networks. Learning, Media and Technology, 34(2), 119-140.

Hew, K. F., \& Cheung, W. S. (2007). Attracting student participation in asynchronous online discussions: A case study of peer facilitation. Computers and Education, 51, 1111-1124.

Hung, H., \& Yuen, S. (2010). Educational use of social networking technology in higher education. Teaching in Higher Education, 15(6), 703-714.

Kennedy, G., Krause, K., Judd, T., Churchward, A., \& Gray, K. (2008). First year students' experiences with technology: are they really digital natives? Australasian Journal of Educational Technology, 24(1), 108-122. Retrieved from http://www.ascilite.org.au/ajet/ajet24/kennedy.pdf

Madge, C., Meek, J., Wellens, J., \& Hooley, T. (2009). Facebook, social integration and informal learning at university: it is more for socialising and talking to friends about work than for actually doing work. Learning, Media and Technology, 34(2), 141-155.

Mazer, J., Murphy, R., \& Simonds, C. (2009). The effects of teacher self-disclosure via Facebook on teacher credibility. Learning, Media and Technology, 34(2), 175-183.

Mazzolini, M., \& Maddison, S. (2003). Sage, guide or ghost? The effect of instructor intervention on student participation in online discussion forums. Computers and Education, 40, 237-253.

Mazzolini, M., \& Maddison, S. (2007). When to jump in: The role of the instructor in online discussion forums. Computers and Education, 49(2), 193-213. 
McCarthy, J. (2010). Blended learning environments: using social networking sites to enhance the first year experience. Australasian Journal of Educational Technology, 26(6), 729-740. Retrieved from http://www.ascilite.org.au/ajet/ajet26/mccarthy.pdf

Merchant, G. (2012). Unravelling the social network: theory and research. Learning, Media and Technology, 37(1), 4-19.

Moore, K., \& McElroy, J. (2012). The influence of personality on Facebook usage, wall postings and regret. Computers in Human Behaviour, 28, 267-274.

Prensky, M. (2001). Digital natives, digital immigrants. On the Horizon, 9(5), 2-6.

Prensky, M. (2009). H. Sapiens digital: From digital immigrants and digital natives to digital wisdom. Innovate, 5(3), 1-9. Retrieved from http://www.innovateonline.info/pdf/vol5_issue3/H._Sapiens_Digital_From_Digital_Immigrants_and_Digital_Natives_to_Digital_Wisdom.pdf

Roblyer, M., McDaniel, M., Webb, M., Herman, J., \& Witty, J. (2010). Findings on Facebook in higher education: A comparison of college faculty and student uses and perceptions of social networking sites. Internet and Higher Education, 13(3), 134-140.

Selwyn, N. (2009). Faceworking: exploring students' education-related use of Facebook. Learning, Media and Technology, 34(2), 157-174.

Smith, S., \& Caruso, J. (2010). The ECAR study of undergraduate students and information technology, 2010. Educause. Retrieved from http://anitacrawley.net/Resources/Reports/ECAR\%20study\%20highlights.pdf

White, D., Sillipigni, L., Lanclos, D., Le Cornu, A., \& Hood, E. (2012). Digital visitors and residents, progress report. Retrieved from JISC http://www.jisc.ac.uk/media/documents/projects/visitorsandresidentsinterim\%20report.pdf

Yu, A., Tian, S., Vogel, D., \& Kwok, R. (2010). Can learning be virtually boosted? An investigation of online social networking impacts. Computers and Education, 55, 1494-1503.

Corresponding author: Zoe Staines, zoe.staines@qut.edu.au

Australasian Journal of Educational Technology (C) 2013.

Please cite as: Staines, Z., \& Lauchs, M. (2013). Students' engagement with Facebook in a university undergraduate policing unit. Australasian Journal of Educational Technology, 29(6), 792-805. 